\title{
Research Article \\ Credit Risky Securities Valuation under a Contagion Model with Interacting Intensities
}

\author{
Anjiao Wang ${ }^{1,2}$ and Zhongxing $\mathbf{Y e}^{1,3}$ \\ ${ }^{1}$ Department of Mathematics, Shanghai Jiao Tong University, Shanghai 200240, China \\ ${ }^{2}$ School of Jiashan Guangbiao, Shanghai Sanda Institute, Shanghai 201209, China \\ ${ }^{3}$ School of Business Information Management, Shanghai Institute of Foreign Trade, \\ Shanghai 201620, China
}

Correspondence should be addressed to Anjiao Wang, anjiaowang@126.com

Received 13 April 2011; Revised 20 June 2011; Accepted 20 June 2011

Academic Editor: Mark A. Petersen

Copyright ( 2011 A. Wang and Z. Ye. This is an open access article distributed under the Creative Commons Attribution License, which permits unrestricted use, distribution, and reproduction in any medium, provided the original work is properly cited.

\begin{abstract}
We study a three-firm contagion model with counterparty risk and apply this model to price defaultable bonds and credit default swap (CDS). This model assumes that default intensities are driven by external common factors as well as other defaults in the system. Using the "total hazard" approach, default times can be generated and the joint density function is obtained. We represent the pricing method of defaultable bonds and obtain the closed-form pricing formulas. By the approach of "change of measure," analytical solutions of CDS swap rate (swap premuim) are derived in the continuous time framework and the discrete time framework, respectively.
\end{abstract}

\section{Introduction}

The corporate bonds and their credit derivatives are typical financial tools in the markets which undertake and avoid the credit risk of the companies. There are two basic approaches to modeling the pricing of defaultable securities: the value-of-the-firm (or structural) approach and the intensity-based approach. The structural model is based on the work of Merton [1], Black and Cox [2], and Geske [3]: the default occurs when the firm assets are insufficient to meet payments on debt or the value of the firm asset falls below a prespecified level.

Nevertheless, the value of the firm assets is not observable, which brings difficulties to the pricing of credit derivatives. Reduced-form approach for credit risks avoids the disadvantage of structural approach which models the firm's value directly. They use risk-neutral pricing principle of contingent claims and take the time of default or other credit events as an exogenous random variable. 
Reduced-form models are developed by Artzner and Delbaen [4], Duffie et al. [5], Jarrow and Turnbull [6], and Madan and Unal [7]. Duffie and Lando [8] show that a reducedform model can be obtained from a structural model with incomplete accounting information. The simplest type of reduced-form model is that the default time or the credit migration is the first jump of an exogenously given jump process with an intensity. In Jarrow et al. [9], the intensity for credit migration is constant; see also Litterman and Iben [10] for a Markov chain model of credit migration. In the papers by Duffie et al. [5], Duffie and Singleton [11], and Lando [12], the intensity of default is a random process. The common feature of the reduced-form models is that default cannot be predicted and can occur at any time. Therefore, reduced-form models have been used to price a wide variety of instruments. In recent years, some papers on estimating the parameters of these models are Collin-Dufresne and Solnik [13] and Duffee [14]. Jarrow and Yu [15] set up a reduced-form model in which estimation can be based on bond prices as well as credit default swap prices. A systematic development of mathematical tools for reduced-form models has been given by Elliott et al. [16], and Jamshidian [17] develops change of numeraire methodology for reduced-form models.

In this paper, we mainly discuss the pricing of the defaultable zero-coupon bonds and CDS based on the intensity model with correlated default. The structure of this paper is organized as follows: in Section 2, we give the basic setup and the three-firm contagion model with an interaction term, comparing it with the model in Leung and Kwok [18]. In Section 3, we give the general pricing formulas in various cases. In this general framework, a pricing formula of defaultable bonds is provided for three-firm model. In Section 4, using the approach of "total hazard" and "change of measure," we present the construction of default time, derive the joint density function, and obtain the closed forms of CDS swap rate (swap premium) in the continuous time and the discrete time framework, respectively. We conclude this paper with Section 5 .

\section{Basic Setup and Three-Firm Contagion Model}

\subsection{Basic Setup and Construction of Default Time}

We consider an uncertain economy with a time horizon of $T^{*}$ described by a filtered probability space $\left(\Omega, \mathcal{F},\left\{\mathcal{F}_{t}\right\}_{t=0}^{T^{*}}, P\right.$ ) (in this paper we follow the symbols and notations of Jarrow and $\mathrm{Yu}[15])$ satisfying the usual conditions of right continuity and completeness with respect to $P$-null sets, where $\mathcal{F}=\mathcal{F}_{T^{*}}$ and $P$ is an equivalent martingale measure under which discounted bond prices are martingale. We assume the existence and uniqueness of $P$, so that bond markets are complete and no arbitrage, as shown in discrete time by Harrison and Kreps [19] and in continuous time by Harrison and Pliska [20]. Subsequent specifications of the model are all under the equivalent martingale measure $P$.

On this probability space, there is an $\mathbb{R}^{d}$-valued process $X_{t}$, which presents $d$-dimensional economy-wide state variables. There are also $I$ point processes, $N^{i}(i=$ $1,2, \ldots, I)$, initialized at 0 . These represent the default processes of the firms in the economy such that the default of the $i$ th firm occurs when $N^{i}$ jumps from 0 to 1 .

According to the information contained in the state variables and the default processes, the filtration is

$$
\mathcal{F}=\mathcal{F}_{t}^{X} \vee \Psi_{t}^{1} \vee \mathcal{F}_{t}^{2} \vee \cdots \vee \mathcal{F}_{t}^{I}
$$


where

$$
\begin{aligned}
& \mathcal{F}_{t}^{X}=\sigma\left(X_{s}, 0 \leq s \leq t\right), \\
& \mathcal{F}_{t}^{i}=\sigma\left(N_{s}^{i}, 0 \leq s \leq t\right)
\end{aligned}
$$

are the filtrations generated by $X_{t}$ and $N_{t}^{i}$, respectively.

Let

$$
\begin{gathered}
\mathcal{F}_{t}^{-i}=\mathcal{F}_{t}^{1} \vee \cdots \mathcal{F}_{t}^{i-1} \vee \mathcal{F}_{t}^{i+1} \cdots \vee \mathcal{F}_{t}^{I}, \\
\mathcal{G}_{t}^{i}=\mathcal{F}_{t}^{i} \vee \mathcal{F}_{T^{*}}^{X} \vee \mathcal{F}_{T^{*}}^{-i}=\mathcal{F}_{t}^{i} \vee \mathcal{G}_{0^{\prime}}^{i},
\end{gathered}
$$

where $\mathcal{G}_{0}^{i}=\mathcal{F}_{T^{*}}^{X} \vee \mathcal{F}_{T^{*}}^{-i}$. We know that $\mathcal{G}_{0}^{i}$ contains complete information on the state variables and the default processes of all firms other than that of the $i$ th, all the way up to time $T^{*}$.

According to the filtration $\mathcal{G}_{t}^{i}$, it is possible to select a nonnegative, $\mathcal{G}_{0}^{i}$-measurable process $\lambda_{t}^{i}$, satisfying $\int_{0}^{t} \lambda_{s}^{i} d s<\infty, P-$ a.s. for all $t \in\left[0, T^{*}\right]$, so that we can define an inhomogeneous Poisson process $N^{i}$, using the process $\lambda_{t}^{i}$ as its intensity function.

Let $\tau^{i}$ denote the default time of firm $i$, namely, $\tau^{i}$ be the first jump time of $N^{i}$, in a typical reduced-form model, which can be defined as

$$
\tau^{i}=\inf \left\{t: \int_{0}^{t} \lambda_{s}^{i} d s \geq E^{i}\right\}
$$

where $\left\{E^{i}\right\}_{i=1}^{I}$ is independent of $X_{t}\left(t \in\left[0, T^{*}\right]\right)$.

According to the Doob-Meyer decomposition, we have that

$$
M_{t}^{i}=N_{t}-\int_{0}^{t \wedge \tau^{i}} \lambda_{s}^{i} d s
$$

is a $\left(P, \mathscr{f}_{t}\right)$-martingale.

Under the above characterization, the conditional survival probability of firm $i$ is given by

$$
P\left(\tau^{i}>t \mid \mathcal{G}_{0}^{i}\right)=\exp \left(-\int_{0}^{t} \lambda_{s}^{i} d s\right), \quad t \in\left[0, T^{*}\right] .
$$

The unconditional survival probability of firm $i$ is given by

$$
P\left(\tau^{i}>t\right)=E\left[\exp \left(-\int_{0}^{t} \lambda_{s}^{i} d s\right)\right], \quad t \in\left[0, T^{*}\right] .
$$

Now, we give the recursive construction of default time as $\mathrm{Yu}$ in his paper [21]. Specifically, we start with the case of no state variable. Let the notation $\lambda_{i}(t \mid n)$ denote the 
intensity for firm $i$ given the observed default times of $n$ other firms, $t_{k_{0}}, t_{k_{1}}, \ldots, t_{k_{n}}$, where $0=t_{k_{0}}<t_{k_{1}}<\cdots<t_{k_{n}}<t<\tau^{i}$.

The total hazard accumulated by firm $i$ by time $t$ given $n$ observed defaults is defined as

$$
\psi_{i}(t \mid n)=\sum_{m=1}^{n} \Lambda_{i}\left(t_{k_{m}}-t_{k_{m-1}} \mid m-1\right)+\Lambda_{i}\left(t-t_{k_{n}} \mid n\right)
$$

where $\Lambda_{i}(s \mid m)=\int_{t_{k_{m}}}^{t_{k_{m}}+s} \lambda_{i}(u \mid m) d u$ is the total hazard accumulated by firm $i$ for a period of length $s$ following the $m$ th default. At the same time, we assume that there is no default between $t_{k_{m}}$ and $t$.

Define the inverse functions

$$
\Lambda_{i}^{-1}(x \mid n)=\inf \left\{s \geq 0: \Lambda_{i}(s \mid m) \geq x\right\}
$$

for $x>0$. We can use the following recursive procedure to construct a collection of random variables.

Step 1. Let $E_{1}, \ldots, E_{I}$ be the i.i.d. unit exponentials and

$$
k_{1}=\operatorname{argmin}\left\{\Lambda_{i}^{-1}\left(E_{i} \mid 0\right): i=1, \ldots, n\right\} \text {, }
$$

and define

$$
\widehat{\tau}^{1}=\Lambda_{k_{1}}^{-1}\left(E_{k_{1}} \mid 0\right)
$$

Step $m+1(m=1,2, \ldots, I-1)$

Given that Step 1 up to step $m$ have resulted in $\left(\widehat{\tau}^{1}, \ldots, \widehat{\tau}^{m}\right)$, define the set $I_{m}=\left\{k_{1}, \ldots, k_{m}\right\}$ and $\bar{I}_{m}$ as the set of firms excluding $I_{m}$. Let

$$
k_{m+1}=\operatorname{nargmin}\left\{\Lambda_{i}^{-1}\left(E_{i}-\psi_{i}\left(\widehat{\tau}^{m} \mid m\right) \mid m\right)\right\}
$$

and let

$$
\widehat{\tau}^{m+1}=\widehat{\tau}^{m}+\Lambda_{k_{m+1}}^{-1}\left(E_{k_{m+1}}-\psi_{k_{m+1}}\left(\widehat{\tau}^{m} \mid m\right) \mid m\right)
$$

Norros [22], Shaked and Shanthikumar [23], and Yu [24] prove that $\widehat{\tau}=\left(\widehat{\tau}^{1}, \ldots, \widehat{\tau}^{I}\right)$ equals $\tau=\left(\tau^{1}, \ldots, \tau^{I}\right)$ in distribution. So we can generate default time $\tau$ by generating $\widehat{\tau}$ and we will not distinguish them from now on.

\subsection{Three-Firms Contagion Model}

In this subsection, we explore the three-firms contagion model with an interaction term. Consider the case where the default intensity of one firm is affected by the default of other 
two firms, so that when one firm defaults the default probabilities of other two firms will jump. In the three-firms contagion model, the interdependent structure between firm $A$, firm $B$, and firm $C$ is characterized by the correlated default intensities.

Recall Leung and Kwok's three-firms model:

$$
\begin{aligned}
& \lambda_{t}^{A}=a_{0}+a_{1} \nabla_{\left\{\tau^{B} \leq t\right\}}+a_{2} \square_{\left\{\tau^{C} \leq t\right\}}, \\
& \lambda_{t}^{B}=b_{0}+b_{1} \nabla_{\left\{\tau^{A} \leq t\right\}}+b_{2} \nabla_{\left\{\tau^{C} \leq t\right\}}, \\
& \lambda_{t}^{C}=c_{0}+c_{1} \nabla_{\left\{\tau^{A} \leq t\right\}}+c_{2} \nabla_{\left\{\tau^{B} \leq t\right\}},
\end{aligned}
$$

where $a_{0}>0, b_{0}>0, c_{0}>0$ and satisfying $a_{0}+a_{1}+a_{2}>0, b_{0}+b_{1}+b_{2}>0, c_{0}+c_{1}+c_{2}>0$. Similarly, $a_{0}>0, b_{0}>0$, and $c_{0}>0$ reflect the effect of macroeconomic factor and itself on firms $A, B, C$, respectively.

Nevertheless, Leung and Kwok have not allow the effect of two parties' simultaneous default on the third party, namely, there is not an interaction term in their model. Thus, if three firms are copartners, then the default risk of each firm may be overestimated and the asset value may be underestimated because there exists the case in which the default events might overlap. If they are competitors, then the case is contrary.

For the above reason, we allow the following three-firms contagion model:

$$
\begin{aligned}
& \lambda_{t}^{A}=a_{0}+a_{1} \nabla_{\left\{\tau^{B} \leq t, \tau^{C}>t\right\}}+a_{2} \nabla_{\left\{\tau^{C} \leq t, \tau^{B}>t\right\}}+a_{3} \nabla_{\left\{\tau^{B} \leq t, \tau^{C} \leq t\right\}}, \\
& \lambda_{t}^{B}=b_{0}+b_{1} \nabla_{\left\{\tau^{A} \leq t, \tau^{C}>t\right\}}+b_{2} \nabla_{\left\{\tau^{C} \leq t, \tau^{A}>t\right\}}+b_{3} \nabla_{\left\{\tau^{A} \leq t, \tau^{C} \leq t\right\}}, \\
& \lambda_{t}^{C}=c_{0}+c_{1} \nabla_{\left\{\tau^{A} \leq t, \tau^{B}>t\right\}}+c_{2} \nabla_{\left\{\tau^{B} \leq t, \tau^{A}>t\right\}}+c_{3} \nabla_{\left\{\tau^{A} \leq t, \tau^{B} \leq t\right\}},
\end{aligned}
$$

where $a_{0}>0, b_{0}>0, c_{0}>0$ and satisfying $a_{0}+a_{1}+a_{2}+a_{3}>0, b_{0}+b_{1}+b_{2}+b_{3}>0$, $c_{0}+c_{1}+c_{2}+c_{3}>0 . a_{0}>0, b_{0}>0$, and $c_{0}>0$ reflect the effect of macroeconomic factor and itself on firms $A, B, C$, respectively.

Nextly, we employ the three-firms model specified by $(2.14 \mathrm{a})-(2.14 \mathrm{c})$ to price defaultable bonds and CDS swap rate.

\section{Bond Pricing under Three-Firm Model}

\subsection{The General Pricing Formulas}

Definition 3.1. A defaultable claim maturing at $T$ is the quadruple $(X, A, Z, \tau)$, where $X$ is an $\mathcal{F}_{T}$-measurable random variable, $A=\left(A_{t}\right)_{t \in[0, T]}$ is an $\mathcal{F}$-adapted, continuous process of finite variation with $A_{0}=0, Z=\left(Z_{t}\right)_{t \in[0, T]}$ is an $\mathcal{F}$-predictable process, and $\tau$ is a random time.

Definition 3.2. The dividend process $D=\left(D_{t}\right)_{t \in \mathbb{R}^{+}}$of the above defaultable claim maturing at $T$ equals, for every $t \in \mathbb{R}^{+}$,

$$
D_{t}=X 0_{\{T<\tau\}}^{0}{ }_{[T, \infty)}(t)+\int_{(0, t \wedge T]}\left(1-N_{u}\right) d A_{u}+\int_{(0, t \wedge T]} Z_{u} d N_{u}
$$

where $X$ is the promised payoff, $A$ represents the process of promised dividends, and the process $Z$ is the recovery process. 
Definition 3.3. The exdividend price process $S$ of a defaultable claim $(X, A, Z, \tau)$ equals, for every $t \in[0, T]$,

$$
S_{t}=E_{t}\left[\int_{(t, T]} \frac{B_{t}}{B_{u}} d D_{u}\right]
$$

where $B_{t}:=B(t)=\exp \left(\int_{0}^{t} r_{s} d s\right)$ is the money market account, $r_{t}$ is a constant risk-free spot rate, and $E_{t}$ represents the conditional expectation on $\mathcal{F}_{t}$ under the equivalent martingale measure $P$.

By Definitions 3.2 and 3.3, the exdividend price of a defaultable claim $(X, A, Z, \tau)$ is given by the following.

Lemma 3.4. The exdividend price of the defaultable claim $(X, A, Z, \tau)$ equals, for $t \in[0, T)$,

$$
S_{t}=\emptyset_{\{t<\tau\}} \frac{B_{t}}{G_{t}} E_{t}\left[B_{T}^{-1} G_{T} X+\int_{t}^{T} B_{u}^{-1} G_{u}\left(Z_{u} \lambda_{u} d u+d A_{u}\right)\right] \text {, }
$$

where $G_{t}=P\left\{\tau>t \mid \mathcal{F}_{t}\right\}$.

From Lemma 3.4, We can explore the following special cases.

(1) For the default-free zero-coupon bond which pays one dollar, the dividend process is $D_{t}=0_{\{t \geq T\}}$. Let $p(t, T)$ be the time- $t$ price, then $p(t, T)$ is given by

$$
p(t, T)=E_{t}\left[\frac{B_{t}}{B_{T}}\right] .
$$

(2) If the dividend process is $D_{t}=\int_{t}^{T} r_{u} d u+\mathbb{Q}_{\{t \geq T\}}$, then the value of the bond is always 1 .

(3) For the defaultable zero-coupon bond which pays one dollar if not default and pays $\delta$ times the price of a default-free bond at maturity, where $\delta$ is introduced by Jarrow and Turnbull [6] and Jarrow et al. [9] as "recovery of Treasury," let $v^{i}(t, T)$ denote the time-t price, issued by firm $i, \delta^{i} \in[0,1]$ is the recovery rate of the firm $i$, then $v^{i}(t, T)$ is given by

$$
\begin{aligned}
v^{i}(t, T) & =E_{t}\left[\exp \left(-\int_{t}^{T} r_{u} d u\right)\left(\delta^{i} 0_{\left\{\tau^{i} \leq T\right\}}+\nabla_{\left\{\tau^{i}>T\right\}}\right)\right] \\
& \left.=E_{t}\left[\frac{B_{t}}{B_{T}}\left(\delta^{i}\right\rceil_{\left\{\tau^{i} \leq T\right\}}+\nabla_{\left\{\tau^{i}>T\right\}}\right)\right] .
\end{aligned}
$$

(4) If the dividend process $D_{t}=X 0_{\left\{\tau^{i}>T, t \geq T\right\}}+\int_{(0, t \wedge T]} Z_{u} d N_{u}$, using the Doob-Meyer decomposition of $N_{t}$, then the value of the defaultable bond is

$$
\begin{aligned}
S_{t} & =E_{t}\left[\int_{t}^{T} \exp \left(-\int_{t}^{u} r_{v} d v\right) Z_{u} \lambda_{u} \nabla_{\{u<\tau\}} d u+\exp \left(-\int_{t}^{T} r_{v} d v\right) X 0_{\{\tau>T\}}\right] \\
& =B_{t} E_{t}\left[\int_{t}^{T} B_{u}^{-1} Z_{u} \lambda_{u} 0_{\{u<\tau\}} d u+B_{T}^{-1} X 0_{\{\tau>T\}}\right] .
\end{aligned}
$$




\subsection{Bond Pricing under Three-Firms Model}

We assume that there are three firms $A, B$, and $C$. Now, we consider the case that each firm holds the other two firms' defaultable bonds, so that when one party defaults, the other two parties' default probability will jump. The default intensities are described as (2.14a)-(2.14c).

We adopt the change of measure introduced by Collin-Dufresne et al. [25] to define a firm-specific probability measure $P^{i}$ which puts zero probability on the paths where default occurs prior to the maturity $T$. Specifically, the change of measure is defined by

$$
Z_{T}:=\left.\frac{d P^{i}}{d P}\right|_{\mathcal{f}_{T}}=0_{\left\{\tau^{i}>T\right\}} \exp \left(\int_{0}^{T} \lambda_{s}^{i} d s\right)
$$

where $P^{i}$ is a firm-specific (firm $i$ ) probability measure which is absolutely continuous with respect to $P$ on the stochastic interval $\left[0, \tau^{i}\right)$. To proceed the calculations under the measure $P^{i}$, we enlarge the filtration to $\mathcal{F}^{i}=\left(\mathcal{F}_{t}^{i}\right)_{t \geq 0}$ as the completion of $\mathcal{F}=\left(\mathcal{F}_{t}\right)_{t \geq 0}$ by the null sets of the probability measure $P^{i}$.

Applying the result of Jarrow and Yu [15], we know that the defaultable bond price of firm $i$ is given by

$$
v^{i}(t, T)=\delta^{i} p(t, T)+\nabla_{\left\{\tau^{i}>t\right\}}\left(1-\delta^{i}\right) E_{t}\left[\exp \left(-\int_{t}^{T}\left(r_{s}+\lambda_{s}^{i}\right) d s\right)\right], \quad t \leq T
$$

or

$$
\frac{v^{i}(t, T)}{p(t, T)}=\delta^{i}+\left(1-\delta^{i}\right) \nabla_{\left\{\tau^{i}>t\right\}} E_{t}\left[\exp \left(-\int_{t}^{T} \lambda_{s}^{i} d s\right)\right]
$$

Because of the symmetry of default intensities, we need only to compute one firm's

value of the three firms. In the remainder of this subsection, we will derive the closed-form pricing formula of firm $C$.

For firm $C$, the time-t value $v^{C}(t, T)$ of the defaultable bond $C$ maturity at $T$ satisfies

$$
v^{C}(t, T)=p(t, T)\left(\delta^{C}+\left(1-\delta^{C}\right) \nabla_{\left\{\tau^{C}>t\right\}} E_{t}\left[\exp \left(-\int_{t}^{T} \lambda_{s}^{C} d s\right)\right]\right),
$$

where

$$
\begin{aligned}
& E_{t}\left[\exp \left(-\int_{t}^{T} \lambda_{s}^{C} d s\right)\right]=e^{-c_{0}(T-t)} E_{t}
\end{aligned}
$$

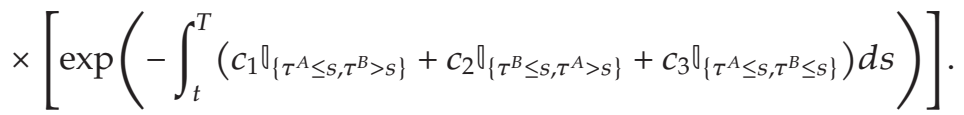


(I) Conditional on $\tau^{A}>t, \tau^{B}>t$, namely, neither firm $A$ nor firm $B$ has defaulted by time $t$, the default intensities $\lambda_{t}^{A}$ and $\lambda_{t}^{B}$ under the measure $P^{C}$ and $\tau^{C}>t$ are given by

$$
\begin{aligned}
& \lambda_{t}^{A}=a_{0}+a_{1} 0_{\left\{\tau^{B} \leq t\right\}}, \\
& \lambda_{t}^{B}=b_{0}+b_{1} 0_{\left\{\tau^{A} \leq t\right\}} .
\end{aligned}
$$

According to the result of Leung and Kwok [18], the conditional joint density function $f_{t}\left(t_{1}, t_{2}\right)$ of $\left(\tau^{A}, \tau^{B}\right)$ is

$$
f_{t}\left(t_{1}, t_{2}\right)= \begin{cases}f_{1, t}\left(t_{1}, t_{2}, t_{3}\right)=b_{0}\left(a_{0}+a_{1}\right) e^{-\left(a_{0}+a_{1}\right)\left(t_{1}-t\right)-\left(b_{0}-a_{1}\right)\left(t_{2}-t\right)}, & t_{2} \leq t_{1} \\ f_{2, t}\left(t_{1}, t_{2}, t_{3}\right)=a_{0}\left(b_{0}+b_{1}\right) e^{-\left(b_{0}+b_{1}\right)\left(t_{2}-t\right)-\left(a_{0}-b_{1}\right)\left(t_{1}-t\right)}, & t_{2}>t_{1} .\end{cases}
$$

The integration region of (3.11) is then appropriately divided into five pieces: $D_{1}: t \leq \tau^{A} \leq T$, $\tau^{A} \leq \tau^{B} \leq T ; D_{2}: t \leq \tau^{B} \leq T, \tau^{B} \leq \tau^{A} \leq T ; D_{3}: t \leq \tau^{A} \leq T, \tau^{B} \geq T ; D_{4}: t \leq \tau^{B} \leq T, \tau^{A} \geq T ;$ $D_{5}: \tau^{A} \geq T, \tau^{B} \geq T:$

$$
\begin{aligned}
& E_{t}\left[\exp \left(-\int_{t}^{T} \lambda_{s}^{C} d s\right)\right]=e^{-c_{0}(T-t)} E_{t}
\end{aligned}
$$

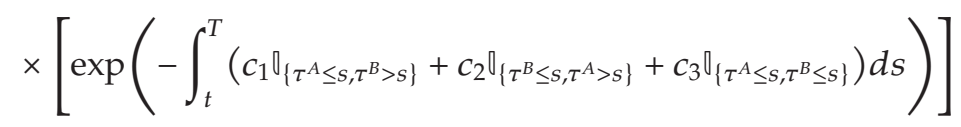

$$
\begin{aligned}
& =: e^{-c_{0}(T-t)}\left(I_{1}+I_{2}+I_{3}+I_{4}+I_{5}\right) \\
& =: J_{1} \text {, }
\end{aligned}
$$

where

$$
\begin{aligned}
I_{1} & =\iint_{D_{1}} e^{-c_{1}\left(t_{2}-t_{1}\right)-c_{3}\left(T-t_{2}\right)} f_{2, t}\left(t_{1}, t_{2}\right) d t_{1} d t_{2} \\
& =a_{0}\left(b_{0}+b_{1}\right) \int_{t}^{T} \int_{t_{1}}^{T} e^{-c_{1}\left(t_{2}-t_{1}\right)-c_{3}\left(T-t_{2}\right)} e^{-\left(a_{0}-b_{1}\right)\left(t_{1}-t\right)-\left(b_{0}+b_{1}\right)\left(t_{2}-t\right)} d t_{2} d t_{1} \\
& =\frac{a_{0}\left(b_{0}+b_{1}\right)}{b_{0}+b_{1}+c_{1}-c_{3}}\left[\frac{e^{-c_{3}(T-t)}-e^{-\left(a_{0}+b_{0}\right)(T-t)}}{a_{0}+b_{0}-c_{3}}-\frac{e^{-\left(b_{0}+b_{1}+c_{1}\right)(T-t)-e^{-\left(a_{0}+b_{0}\right)(T-t)}}}{a_{0}-b_{1}-c_{1}}\right], \\
I_{2} & =\iint_{D_{2}} e^{-c_{2}\left(t_{1}-t_{2}\right)-c_{3}\left(T-t_{1}\right)} f_{1, t}\left(t_{1}, t_{2}\right) d t_{1} d t_{2} \\
& =\frac{b_{0}\left(a_{0}+a_{1}\right)}{a_{0}+a_{1}+c_{2}-c_{3}}\left[\frac{e^{-c_{3}(T-t)}-e^{-\left(a_{0}+b_{0}\right)(T-t)}}{a_{0}+b_{0}-c_{3}}-\frac{e^{-\left(a_{0}+a_{1}+c_{2}\right)(T-t)-e^{-\left(a_{0}+b_{0}\right)(T-t)}}}{b_{0}-a_{1}-c_{2}}\right],
\end{aligned}
$$


Journal of Applied Mathematics

$$
\begin{aligned}
I_{3} & =\iint_{D_{3}} e^{-\left(c_{1}\left(t_{2}-t_{1}\right)\right)} f_{2, t}\left(t_{1}, t_{2}\right) d t_{1} d t_{2} \\
& =\frac{a_{0}\left(b_{0}+b_{1}\right)}{\left(a_{0}-b_{1}-c_{1}\right)\left(b_{0}+b_{1}+c_{1}\right)}\left[e^{-\left(b_{0}+b_{1}+c_{1}\right)(T-t)}-e^{-\left(a_{0}+b_{0}\right)(T-t)}\right], \\
I_{4} & =\iint_{D_{4}} e^{-\left(c_{2}\left(t_{1}-t_{2}\right)\right)} f_{1, t}\left(t_{1}, t_{2}\right) d t_{1} d t_{2} \\
& =\frac{b_{0}\left(a_{0}+a_{1}\right)}{\left(b_{0}-a_{1}-c_{2}\right)\left(a_{0}+a_{1}+c_{2}\right)}\left[e^{-\left(a_{0}+a_{1}+c_{2}\right)(T-t)}-e^{-\left(a_{0}+b_{0}\right)(T-t)}\right], \\
I_{5} & =\iint_{D_{5}} f_{t}\left(t_{1}, t_{2}\right) d t_{1} d t_{2}=e^{-\left(a_{0}+b_{0}\right)(T-t)} .
\end{aligned}
$$

(II) Conditional on $\tau^{B}>t, \tau^{A} \leq t$, namely, firm $A$ has defaulted and firm $B$ has not defaulted by time $t$, the default intensities $\lambda_{t}^{B}$ are given by

$$
\lambda_{t}^{B}=b_{0}+b_{1} \mathbb{0}_{\left\{\tau^{A} \leq t, \tau^{C}>t\right\}}=b_{0}+b_{1}
$$

and the density function $f_{t}\left(t_{2}\right)$ of $\tau^{B}$ is

$$
f_{t}\left(t_{2}\right)=\left(b_{0}+b_{1}\right) e^{-\left(b_{0}+b_{1}\right)\left(t_{2}-t\right)}
$$

so

$$
\begin{aligned}
E_{t}\left[\exp \left(-\int_{t}^{T} \lambda_{s}^{C} d s\right)\right]= & e^{-c_{0}(T-t)} E_{t}\left[\exp \left(-\int_{t}^{T}\left(c_{1} 0_{\left\{\tau^{A} \leq s, \tau^{B}>s\right\}}+c_{3} \mathbb{D}_{\left\{\tau^{A} \leq s, \tau^{B} \leq s\right\}}\right) d s\right)\right] \\
= & \left(b_{0}+b_{1}\right) e^{-c_{0}(T-t)} \\
& \times\left[\int_{t}^{T} e^{-c_{1}\left(t_{2}-t\right)-c_{3}\left(T-t_{2}\right)} e^{-\left(b_{0}+b_{1}\right)\left(t_{2}-t\right)} d t_{2}+\int_{T}^{\infty} e^{-c_{1}(T-t)} e^{-\left(b_{0}+b_{1}\right)\left(t_{2}-t\right)} d t_{2}\right] \\
= & \left(b_{0}+b_{1}\right) e^{-c_{0}(T-t)}\left[\frac{e^{-c_{3}(T-t)}-e^{-\left(b_{0}+b_{1}+c_{1}\right)(T-t)}}{b_{0}+b_{1}+c_{1}-c_{3}}+\frac{e^{-\left(b_{0}+b_{1}-c_{1}\right)(T-t)}}{b_{0}+b_{1}}\right] \\
= & : J_{2} .
\end{aligned}
$$

(III) Conditional on $\tau^{B} \leq t, \tau^{A}>t$, namely, firm $B$ has defaulted and firm $A$ has not defaulted by time $t$, similar to the computation in (II), we have

$$
\begin{aligned}
E_{t}\left[\exp \left(-\int_{t}^{T} \lambda_{s}^{C} d s\right)\right] & =\left(a_{0}+a_{1}\right) e^{-c_{0}(T-t)}\left[\frac{e^{-c_{3}(T-t)}-e^{-\left(a_{0}+a_{1}+c_{2}\right)(T-t)}}{a_{0}+a_{1}+c_{2}-c_{3}}+\frac{e^{-\left(a_{0}+a_{1}-c_{2}\right)(T-t)}}{a_{0}+a_{1}}\right] \\
& =: J_{3}
\end{aligned}
$$


(IV) Conditional on $\tau^{A} \leq t, \tau^{B} \leq t$, namely, firm $A$ and firm $B$ have defaulted by time $t$, we have

$$
E_{t}\left[\exp \left(-\int_{t}^{T} \lambda_{s}^{C} d s\right)\right]=e^{-\left(c_{0}+C_{3}\right)(T-t)}=: J_{4}
$$

From (3.10), (3.11), and the discussions in (I)-(IV), we have the following theorem.

Theorem 3.5. Let intensity processes $\lambda_{t}^{i}(i=A, B, C)$ be given by (2.14a)-(2.14c), the time- $t$ defaultable bond price issued by firm $C$ is given by

$$
\begin{aligned}
v^{C}(t, T)= & p(t, T)\left(\delta^{C}+\left(1-\delta^{C}\right) \nabla_{\left\{\tau^{C}>t\right\}}\left(\nabla_{\left\{\tau^{A}>t, \tau^{B}>t\right\}} J_{1}\right.\right. \\
& \left.\left.+\nabla_{\left\{\tau^{A} \leq t, \tau^{B}>t\right\}} J_{2}+\nabla_{\left\{\tau^{A}>t, \tau^{B} \leq t\right\}} J_{3}+\nabla_{\left\{\tau^{A} \leq t, \tau^{B} \leq t\right\}} J_{4}\right)\right),
\end{aligned}
$$

where $J_{1}, J_{2}, J_{3}, J_{4}$ are given by (3.14)-(3.20).

\section{CDS Valuation under Three-Firms Model}

\subsection{The Basics}

As one of the important credit derivatives, CDS is a contract agreement which allows the transfer of credit risk of a risky asset (basket of risky assets) from one party to the other. A financial institution may use a CDS to transfer credit risk of a risky asset while continues to retain the legal ownership of the asset. To determine a fair swap rate of a CDS in the presence of counterparty risks, the interdependent default risk structures between these parties must be considered simultaneously.

On CDS valuation, there have been numerous works in recent years. Based on the reduced-form approach with correlated market and credit risks, the closed-form valuation formula for the swap rate of a CDS is obtained by Jarrow and Yildirim [26]. They assume that the default intensity is "almost" linear in the short interest rate. Recently, considering the impact of counterparty risk on the pricing of a CDS, Jarrow and Yu in [15] assume an interdependent default structure that avoids "looping default" by involving primarysecondary framework and simplifies the payoff structure where the protection seller's compensation is made only at the maturity of the swap contract. They discover that the default risk of the protection seller and reference entity is ignored. Hull and White [27] apply the credit index model for valuing CDS with counterparty risk. M. A. Kim and T. S. Kim [28] conclude that if the default correlation between the counterparty and reference bond is ignored, then the pricing error in a CDS can be quite substantial. Chen and Filpovic in their paper [29] develop a generalized affine model to price credit default swaps under default correlations and counterparty risk. Yu [21] uses the "total hazard" approach to construct the default process from independent and identically distributed exponential random variables and obtains an analytic expression of the joint distribution of default times in his twofirms and three-firms contagion models. Leung and Kwok [18] use the "change of measure" approach introduced by Collin-Dufresne et al. [25] to price the CDS in two-firms model and three-firms contagion model, respectively, and obtain the closed-form formulas. 


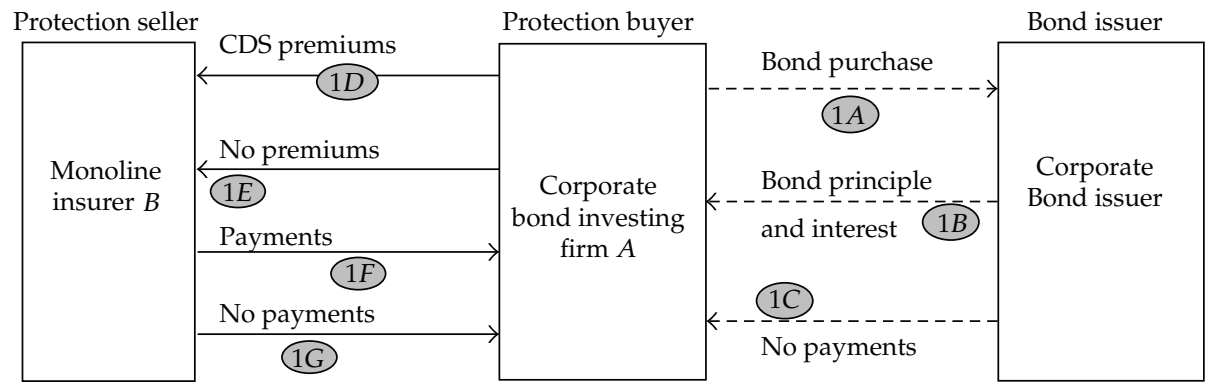

Figure 1: The structure of CDS.

We assume that party $A$ (CDS protection buyer) holds a corporate bond of party $C$ (reference asset) and party $C$ is subject to default. Party $A$ faces the credit risk arising from default of party $C$. To seek protection against such default risk, party $A$ enters a CDS contract in which he agrees to make premium payments, known as the swap premium to party $B$ (CDS protection seller). In exchange, party $B$ promises to compensate $A$ for its loss in the event of default of the bond (reference asset).

Similar to the description in [30], a diagrammatic overview of CDS under the threefirms contagion model (2.14a)-(2.14c) is provided by Figure 1.

We employ the three-firms model specified by $(2.14 a)-(2.14 c)$ to price the CDS and study the effect of the default of each party on the swap rate. Suppose that party $A$ (a corporate bond investing firm) holds a corporate bond (reference asset) issued by party $C$ (a corporate bond issuer) (refer to $1 A$ in Figure 1 ) and firm $C$ is subject to default. At bond maturity, if firm $C$ does not default, then it will pay the bond principle and interest to firm $A$ (see $1 B$ ). Otherwise, it has no payments (refer to $1 C$ ). On the other hand, to hedge the default risk of firm $C$, firm $A$, and firm $B$ (the protection seller, such as a monoline insurer), enter into a CDS contract. Firm $A$ and $B$ are also subject to default. If firm $C$ and $A$ have no default, then firm $A$ makes fixed premium payments, known as the swap premium to firm $B$ (see $1 D$ ). Either firm $A$ or firm $C$ defaults, there is no premium payments to firm $B$ (refer to $1 E$ ). In exchange, firm $B$ promises to compensate $A$ (if $A$ does not default) for its loss in the event of default of the bond $C$ (reference asset) as long as $B$ does not default (refer to $1 F$ ). If the protection seller $B$ defaults prior to the default of either the reference asset $C$ or the protection buyer $A$, then the protection seller $B$ can simply walk away from the contract and has no obligation to pay the compensation to the protection buyer (see $1 G$ ).

In this section, we will analyze the effect of correlated risks between three parties in a CDS using a similar contagion model as in Leung and Kwok's model [18]. Differently from their model on CDS valuation with counterparty risk, we allow an interaction term in the default intensity model for three firms, namely, we discuss how the simultaneous default of two parties impacts on the third one.

\subsection{The Joint Density Function for Three-Firms Model}

To price CDS swap rate $s$, we firstly need to provide the joint density function $f\left(t_{1}, t_{2}, t_{3}\right)$ of three firms $A, B$, and $C$. We adopt the "total hazard" approach by Yu [21] and Zheng and Jiang [31] as description in Section 2.1; the result is the following Lemma. 
Lemma 4.1. Assume that $\lambda_{t}^{i}(i=A, B, C)$ are given by model (2.14a)-(2.14c). Then the joint density function of $\tau=\left(\tau^{A}, \tau^{B}, \tau^{C}\right)$ is given by

$$
f\left(t_{1}, t_{2}, t_{3}\right)= \begin{cases}f_{1}\left(t_{1}, t_{2}, t_{3}\right), & t_{1} \leq t_{2} \leq t_{3} \leq T, \\ f_{2}\left(t_{1}, t_{2}, t_{3}\right), & t_{1} \leq t_{3} \leq t_{2} \leq T, \\ f_{3}\left(t_{1}, t_{2}, t_{3}\right), & t_{2} \leq t_{1} \leq t_{3} \leq T, \\ f_{4}\left(t_{1}, t_{2}, t_{3}\right), & t_{2} \leq t_{3} \leq t_{1} \leq T, \\ f_{5}\left(t_{1}, t_{2}, t_{3}\right), & t_{3} \leq t_{1} \leq t_{2} \leq T, \\ f_{6}\left(t_{1}, t_{2}, t_{3}\right), & t_{3} \leq t_{2} \leq t_{1} \leq T,\end{cases}
$$

where

$$
\begin{aligned}
& f_{1}\left(t_{1}, t_{2}, t_{3}\right)=a_{0}\left(b_{0}+b_{1}\right)\left(c_{0}+c_{3}\right) e^{-\left(a_{0}-b_{1}-c_{1}\right) t_{1}-\left(b_{0}+b_{1}+c_{1}-c_{3}\right) t_{2}-\left(c_{0}+c_{3}\right) t_{3},}, \\
& f_{2}\left(t_{1}, t_{2}, t_{3}\right)=a_{0}\left(c_{0}+c_{1}\right)\left(b_{0}+b_{3}\right) e^{-\left(a_{0}-b_{1}-c_{1}\right) t_{1}-\left(b_{0}+b_{3}\right) t_{2}-\left(c_{0}+c_{1}+b_{1}-b_{3}\right) t_{3},} \\
& f_{3}\left(t_{1}, t_{2}, t_{3}\right)=b_{0}\left(a_{0}+a_{1}\right)\left(c_{0}+c_{3}\right) e^{-\left(a_{0}+a_{1}-c_{1}\right) t_{1}-\left(b_{0}-a_{1}+c_{1}-c_{3}\right) t_{2}-\left(c_{0}+c_{3}\right) t_{3},} \\
& f_{4}\left(t_{1}, t_{2}, t_{3}\right)=b_{0}\left(c_{0}+c_{2}\right)\left(a_{0}+a_{3}\right) e^{-\left(a_{0}+a_{3}\right) t_{1}-\left(b_{0}-c_{2}-a_{1}\right) t_{2}-\left(c_{0}+c_{2}+a_{1}-a_{3}\right) t_{3},} \\
& f_{5}\left(t_{1}, t_{2}, t_{3}\right)=c_{0}\left(a_{0}+a_{2}\right)\left(b_{0}+b_{3}\right) e^{-\left(a_{0}+a_{2}+b_{2}-b_{3}\right) t_{1}-\left(b_{0}+b_{3}\right) t_{2}-\left(c_{0}-a_{2}-b_{2}\right) t_{3},} \\
& f_{6}\left(t_{1}, t_{2}, t_{3}\right)=c_{0}\left(a_{0}+a_{3}\right)\left(b_{0}+b_{2}\right) e^{-\left(a_{0}+a_{3}\right) t_{1}-\left(b_{0}+b_{2}+a_{2}-a_{3}\right) t_{2}-\left(c_{0}-a_{2}-b_{2}\right) t_{3}} .
\end{aligned}
$$

Proof. With the total hazard method (2.10) and (2.12) introduced in Section 2, we can express default time $\tau$ in terms of standard exponential variables $E$, and vice versa. If $\tau^{A}<\tau^{B}<\tau^{C}$, then we have

$$
\begin{aligned}
E_{1} & =\int_{0}^{\tau^{A}} a_{0} d u=a_{0} \tau^{A}, \\
E_{2} & =\int_{0}^{\tau^{B}} b_{0} d u+\int_{\tau^{A}}^{\tau^{B}} b_{1} \nabla_{\left\{\tau^{C}>u\right\}} d u=b_{0} \tau^{B}+b_{1}\left(\tau^{B}-\tau^{A}\right), \\
E_{3} & =\int_{0}^{\tau^{C}} c_{0} d u+\int_{\tau^{A}}^{\tau^{C}} c_{1} \nabla_{\left\{\tau^{B}>u\right\}} d u+\int_{\tau^{B}}^{\tau^{C}}\left(c_{2} \nabla_{\left\{\tau^{A}>u\right\}}+c_{3} \nabla_{\left\{\tau^{A} \leq u\right\}}\right) d u \\
& =c_{0} \tau^{C}+c_{1}\left(\tau^{B}-\tau^{A}\right)+c_{3}\left(\tau^{C}-\tau^{B}\right) .
\end{aligned}
$$

The Jacobi determinant of $E$ with respect to $\tau$ is given by

$$
C\left(\tau^{A}, \tau^{B}, \tau^{C}\right)=\left|\frac{\partial E_{1}}{\partial \tau^{A}} \frac{\partial E_{2}}{\partial \tau^{B}} \frac{\partial E_{3}}{\partial \tau^{C}}\right|=a_{0}\left(b_{0}+b_{1}\right)\left(c_{0}+c_{3}\right) .
$$


The density of $\tau$ is therefore

$$
f\left(\tau^{A}, \tau^{B}, \tau^{C}\right)=C\left(\tau^{A}, \tau^{B}, \tau^{C}\right) e^{-\left(E_{1}+E_{2}+E_{3}\right)}
$$

Substituting $E_{i}$ into $f$, we get

$$
f\left(t_{1}, t_{2}, t_{3}\right)=a_{0}\left(b_{0}+b_{1}\right)\left(c_{0}+c_{3}\right) e^{-\left(a_{0}-b_{1}-c_{1}\right) t_{1}-\left(b_{0}+b_{1}+c_{1}-c_{3}\right) t_{2}-\left(c_{0}+c_{3}\right) t_{3}}, \quad \text { for } 0<t_{1}<t_{2}<t_{3} .
$$

The density function $f$ in other regions can be expressed similarly with permutation. Thus, we complete the proof of the lemma.

\subsection{CDS Valuation}

In this subsection, we employ the three-firms model specified by $(2.14 \mathrm{a})-(2.14 \mathrm{c})$ to price the CDS swap rate $s$ (or swap premium) in continuous time framework and discrete time framework, respectively. We assume that the recovery rate is zero and the risk-free spot rate $r$ is a constant.

\subsubsection{In Continuous Time Framework}

In this framework, the value of the contingent leg at time 0 is equal to

$$
C=\exp \left(-\int_{0}^{\tau^{C}+\theta} r d t\right) \nabla_{\left\{\tau^{A}>\tau^{C}, \tau^{B}>\tau^{C}+\theta, \tau^{C} \leq T\right\}}
$$

and the value of the fee leg at time 0 is equal to

$$
F=s \int_{0}^{T} \exp \left(-\int_{0}^{t} r d u\right) \nabla_{\left\{\tau^{A} \wedge \tau^{B} \wedge \tau^{C}>t\right\}} d t,
$$

where $T$ is the expiration, $\theta$ is the length of the settlement period, and $\tau^{C}+\theta$ represents the settlement date at the end of the settlement period. theorem.

We can derive $s$ by computing the expectation of $C$ and $F$; the result is the following

Theorem 4.2. Let the intensity processes $\lambda_{t}^{i}(i=A, B, C)$ be given by (2.14a)-(2.14c), the density function given by (4.1). Then, the swap rate $s$ is given by

$$
s=\frac{c_{0}\left(a_{0}+a_{2}\right) e^{-\left(b_{0}+b_{3}+r\right) \theta}}{a_{0}+a_{2}+b_{2}-b_{3}}+\left(b_{0}+b_{2}-\frac{\left(a_{0}+a_{2}\right)\left(b_{0}+b_{3}\right)}{a_{0}+a_{2}+b_{2}-b_{3}}\right) \frac{c_{0} e^{-\left(a_{0}+a_{2}+b_{0}+b_{2}+r\right) \theta}}{a_{0}+a_{2}+b_{0}+b_{2}} .
$$

Proof. According to the arbitrage-free principle, we set the present value of protection buyer's payment equal to the present value of the compensation payment made at $\tau^{C}+\theta$, conditional on default of $C$ prior to $T$, no default of $A$ prior to $\tau^{C}$, and no default of $B$ prior to $\tau^{C}+\theta$. 
Since it takes no cost to enter a CDS, the value of $s$ under this three-firms model is determined by

$$
s E\left[\int_{0}^{T} \exp \left(-\int_{0}^{t} r d u\right) \nabla_{\left\{\tau^{A} \wedge \tau^{B} \wedge \tau^{C}>t\right\}} d t\right]=E\left[\exp \left(-\int_{0}^{\tau^{C}+\theta} r d t\right) \nabla_{\left\{\tau^{A}>\tau^{C}, \tau^{B}>\tau^{C}+\theta, \tau^{C} \leq T\right\}}\right],
$$

where $\tau^{C}+\theta$ represents the settlement date at the end of the settlement period.

Recall that the change of measure is defined by

$$
Z_{T}:=\left.\frac{d P^{i}}{d P}\right|_{\mathcal{F}_{T}}=\nabla_{\left\{\tau^{i}>T\right\}} \exp \left(\int_{0}^{T} \lambda_{S}^{i} d s\right)
$$

Thus, by (4.1), (4.11) and the Fubini Theorem, we can derive the left side of (4.10):

$$
\begin{aligned}
& s E\left[\int_{0}^{T} \exp \left(-\int_{0}^{t} r d u\right) 0_{\left\{\tau^{A} \wedge \tau^{B} \wedge \tau^{C}>t\right\}} d t\right] \\
& =s \int_{0}^{t} e^{-r t} E\left[0_{\left\{\tau^{A} \wedge \tau^{B} \wedge \tau^{C}>t\right\}}\right] d t \\
& =s \int_{0}^{T} e^{-r t} E^{A}\left[\nabla_{\left\{\tau^{B}>t, \tau^{C}>t\right\}} \exp \left(-\int_{0}^{t} \lambda_{s}^{A} d s\right)\right] d t \\
& =s \int_{0}^{T} e^{-\left(a_{0}+r\right) t} E^{A}\left[{ }_{\left\{\tau^{B}>t, \tau^{C}>t\right\}}\right] d t \\
& =s \int_{0}^{T} e^{-\left(a_{0}+b_{0}+c_{0}+r\right) t} d t=s \frac{1-e^{-\left(a_{0}+b_{0}+c_{0}+r\right) T}}{a_{0}+b_{0}+c_{0}+r},
\end{aligned}
$$

where the fourth equation is according to the two-firms model of Leung and Kwok in [18],

$$
E^{A}\left[0_{\left\{\tau^{B}>t, \tau^{C}>t\right\}}\right]=e^{-\left(b_{0}+c_{0}\right) t}
$$

The right side of (4.10) equals

$$
\begin{aligned}
& E\left[\exp \left(-\int_{0}^{\tau^{C}+\theta} r d t\right) \nabla_{\left\{\tau^{A}>\tau^{C}, \tau^{B}>\tau^{C}+\theta, \tau^{C} \leq T\right\}}\right] \\
& \quad=\int_{0}^{T} \int_{t_{3}+\theta}^{\infty} \int_{t_{3}}^{\infty} e^{-\left(t_{3}+\theta\right) r} f\left(t_{1}, t_{2}, t_{3}\right) d t_{1} d t_{2} d t_{3} \\
& =\int_{0}^{T} \int_{t_{3}+\theta}^{\infty} \int_{t_{3}}^{t_{2}} e^{-\left(t_{3}+\theta\right) r} f_{5}\left(t_{1}, t_{2}, t_{3}\right) d t_{1} d t_{2} d t_{3}+\int_{0}^{T} \int_{t_{3}+\theta}^{\infty} \int_{t_{2}}^{\infty} e^{-\left(t_{3}+\theta\right) r} f_{6}\left(t_{1}, t_{2}, t_{3}\right) d t_{1} d t_{2} d t_{3} \\
& =: I_{1}+I_{2},
\end{aligned}
$$


where

$$
\begin{aligned}
I_{6}= & \int_{0}^{T} \int_{t_{3}+\theta}^{\infty} \int_{t_{3}}^{t_{2}} e^{-\left(t_{3}+\theta\right) r} f_{5}\left(t_{1}, t_{2}, t_{3}\right) d t_{1} d t_{2} d t_{3} \\
= & e^{-r \theta} \int_{0}^{T} \int_{t_{3}+\theta}^{\infty} \int_{t_{3}}^{t_{2}} e^{-r t_{3}} c_{0}\left(a_{0}+a_{2}\right)\left(b_{0}+b_{3}\right) \cdot e^{-\left(a_{0}+a_{2}+b_{2}-b_{3}\right) t_{1}-\left(b_{0}+b_{3}\right) t_{2}-\left(c_{0}-a_{2}-b_{2}\right) t_{3}} d t_{1} d t_{2} d t_{3} \\
= & \frac{c_{0}\left(a_{0}+a_{2}\right)\left(b_{0}+b_{3}\right)}{a_{0}+a_{2}+b_{2}-b_{3}} e^{-r \theta} \\
& \times \int_{0}^{T} \int_{t_{3}+\theta}^{\infty}\left(e^{-\left(a_{0}+c_{0}-b_{3}+r\right) t_{3}} \cdot e^{-\left(b_{0}+b_{3}\right) t_{2}}-e^{-\left(c_{0}-a_{2}-b_{2}+r\right) t_{3}} \cdot e^{-\left(a_{0}+a_{2}+b_{0}+b_{2}\right) t_{2}}\right) d t_{2} d t_{3} \\
= & \left(\frac{c_{0}\left(a_{0}+a_{2}\right) e^{-\left(b_{0}+b_{3}+r\right) \theta}}{a_{0}+a_{2}+b_{2}-b_{3}}-\frac{c_{0}\left(a_{0}+a_{2}\right)\left(b_{0}+b_{3}\right) e^{-\left(a_{0}+a_{2}+b_{0}+b_{2}+r\right) \theta}}{\left(a_{0}+a_{2}+b_{2}-b_{3}\right)\left(a_{0}+a_{2}+b_{0}+b_{2}\right)}\right) \int_{0}^{T} e^{-\left(a_{0}+b_{0}+c_{0}+r\right)} d t_{3} \\
= & \frac{c_{0}\left(a_{0}+a_{2}\right)\left(b_{0}+b_{3}\right) e^{-r \theta}}{a_{0}+a_{2}+b_{2}-b_{3}}\left(\frac{e^{-\left(b_{0}+b_{3}\right) \theta}}{b_{0}+b_{3}}-\frac{e^{-\left(a_{0}+a_{2}+b_{0}+b_{2}\right) \theta}}{\left(a_{0}+a_{2}+b_{0}+b_{2}\right)}\right) \cdot \frac{1-e^{-\left(a_{0}+b_{0}+c_{0}+r\right) T}}{a_{0}+b_{0}+c_{0}+r} \\
I_{7}= & \int_{0}^{T} \int_{t_{3}+\theta}^{\infty} \int_{t_{2}}^{\infty} e^{-\left(t_{3}+\theta\right) r} f_{6}\left(t_{1}, t_{2}, t_{3}\right) d t_{1} d t_{2} d t_{3} \\
= & e^{-r \theta} \int_{0}^{T} \int_{t_{3}+\theta}^{\infty} c_{0}\left(b_{0}+b_{2}\right) e^{-\left(c_{0}-a_{2}-b_{2}+r\right) t_{3}} e^{-\left(a_{0}+a_{2}+b_{0}+b_{2}\right) t_{2}} d t_{2} d t_{3} \\
= & \frac{c_{0}\left(b_{0}+b_{2}\right) e^{-\left(a_{0}+a_{2}+b_{0}+b_{2}+r\right) \theta}}{a_{0}+a_{2}+b_{0}+b_{2}} \int_{0}^{T} e^{-\left(a_{0}+b_{0}+c_{0}+r\right) t_{3}} d t_{3} \\
\left.a_{0}+b_{2}\right) e^{-\left(a_{0}+a_{2}+b_{0}+b_{2}+r\right) \theta} & \frac{1-e^{-\left(a_{0}+b_{0}+c_{0}+r\right) T}}{a_{0}+b_{0}+b_{0}+c_{0}+r} .
\end{aligned}
$$

By (4.10) and (4.12)-(4.16), we obtain expression (4.9) of $s$.

Remark 4.3. From (4.9), we can see that the swap rate $\mathrm{s}$ is not dependent on the expiration date $\mathrm{T}$. The default of the buyer impacts on the swap rate $s$, so it is not strict if assuming that the buyer has no default throughout the process though the default risk of the protection buyer has little impact on the swap rate. The reference asset's default risk proxied by $c_{0}$ gives the most significant impact on the swap rate, and an increasing higher value of $c_{0}$ gives rise to a higher swap rate. The contagion effect of the protection buyer and the protection seller on the reference asset has no effect on the swap rate $s$ (there are no $c_{1}, c_{2}$, and $c_{3}$ terms). This shows that when valuating CDS in "loop-default" models, without loss of generality, we can assume that the reference asset is the primary firm and the protection buyer and the seller are secondary firms.

Remark 4.4. From (4.9), if the settlement period $\theta$ is zero, the swap rate $s$ is $c_{0}$, which is the default intensity of reference asset determined by macroeconomic factor and itself, and has nothing to do with the credit risk of the protection buyer and seller. 


\subsection{Valuation of CDS in the Discrete Time Framework}

In the discrete time framework, let $T_{0}, T_{1}, T_{2}, \ldots, T_{n}$ be the swap payment dates, where $0=$ $T_{0}<T_{1}<\cdots<T_{n}=T$. We assume that the payment dates are uniformly distributed; that is, $T_{i+1}-T_{i}=\Delta T$ for $1 \leq i \leq n-1$ and $n \Delta T=T$.

The value of the contingent leg at time 0 is given by

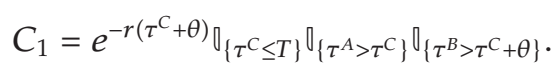

The value of the fee leg at time 0 is given by

$$
\left.F_{1}=\sum_{i=1}^{n} S(\Delta T)\left[e^{-r T_{i}} \int_{\left\{\tau^{A} \wedge \tau^{B} \wedge \tau^{C}>T_{i}\right\}}+e^{-r \tau^{C}}\left(\frac{\tau^{C}-T_{i-1}}{\Delta T}\right) \mathbb{D}_{\left\{T_{i-1}<\tau^{C}<T_{i}\right\}}\right\}_{\left\{\tau^{A} \wedge \tau^{B}>\tau^{C}\right\}}\right] .
$$

According to the arbitrage-free pricing principle, we have the following theorem.

Theorem 4.5. Let the intensity processes $\lambda_{t}^{i}(i=A, B, C)$ be given by $(2.14 \mathrm{a})-(2.14 \mathrm{c})$, the density function given by (4.1). Then,

$$
\begin{aligned}
& E\left[C_{1}\right]=\left[\frac{c_{0} e^{-\left(a_{0}+a_{2}+b_{0}+b_{2}+r\right) \theta}}{a_{0}+a_{2}+b_{0}+b_{2}}\left(b_{0}+b_{2}-\frac{\left(a_{0}+a_{2}\right)\left(b_{0}+b_{3}\right)}{a_{0}+a_{2}+b_{2}-b_{3}}\right)+\frac{c_{0}\left(a_{0}+a_{2}\right) e^{-\left(b_{0}+b_{3}+r\right) \theta}}{a_{0}+a_{2}+b_{2}-b_{3}}\right] \frac{1-e^{-\alpha T}}{\alpha} \\
& E\left[F_{1}\right]=S(\Delta T)\left[\frac{c_{0}\left(1-e^{-\alpha \Delta T}-\alpha \Delta T e^{-\alpha \Delta T}\right)+\alpha^{2} \Delta T}{\alpha^{2} \Delta T}\right] \frac{1-e^{-\alpha T}}{1-e^{-\alpha \Delta T}}
\end{aligned}
$$

where $\alpha:=a_{0}+b_{0}+c_{0}+r$. The swap rate $S(\Delta T)$ is given by equating $E\left[C_{1}\right]$ and $E\left[F_{1}\right]$.

Proof. Similar to the discussion in the continuous time, since it takes no cost to enter a CDS, the value of the swap rate $S(\Delta T)$ under this three-firms model is determined by

$$
\begin{aligned}
& S(\Delta T) \sum_{i=1}^{n} E\left[\left.e^{-r T_{i}}\right|_{\left\{\tau^{A} \wedge \tau^{B} \wedge \tau^{C}>T_{i}\right\}}\right]+S(\Delta T) A(\Delta T) \\
& =E\left[e^{-r\left(\tau^{C}+\theta\right)} \nabla_{\left\{\tau^{C} \leq T\right\}} \nabla_{\left\{\tau^{A}>\tau^{C}\right\}} \nabla_{\left\{\tau^{B}>\tau^{C}+\theta\right\}}\right],
\end{aligned}
$$

where

$$
A(\Delta T)=\sum_{i=1}^{n} E\left[e^{-r \tau^{C}}\left(\frac{\tau^{C}-T_{i-1}}{\Delta T}\right) 0_{\left\{T_{i-1}<\tau^{C}<T_{i}\right\}} \nabla_{\left\{\tau^{A} \wedge \tau^{B}>\tau^{C}\right\}}\right],
$$

where $\theta$ is still the length of the settlement period. The first term in (4.20) gives the present value of the sum of periodic swap payments (terminated when either $A, B$, or $C$ defaults or at maturity), and $S(\Delta T) A(\Delta T)$ is the present value of the accrued swap premium for the 
fraction of period between $\tau^{C}$ and the last payment date. The right term represents the present value which the protection seller $(B)$ pays if the reference asset defaults prior to the maturity:

$$
\begin{gathered}
\sum_{i=1}^{n} E\left[e^{-r T_{i}} 0_{\left\{\tau^{A} \wedge \tau^{B} \wedge \tau^{C}>T_{i}\right\}}\right]=\frac{e^{-\alpha \Delta T}\left(1-e^{-\alpha n \Delta T}\right)}{1-e^{-\alpha \Delta T}}=\frac{e^{-\alpha \Delta T}\left(1-e^{-\alpha T}\right)}{1-e^{-\alpha \Delta T}} . \\
E\left[e^{-r \tau^{C}}\left(\frac{\tau^{C}-T_{i-1}}{\Delta T}\right) 0_{\left\{T_{i-1}<\tau^{C}<T_{i}\right\}} 0_{\left\{\tau^{A} \wedge \tau^{B}>\tau^{C}\right\}}\right] \\
=\frac{1}{\Delta T} \int_{T_{i-1}}^{T_{i}} \int_{t_{3}}^{\infty} \int_{t_{3}}^{\infty} e^{-r t_{3}}\left(t_{3}-T_{i-1}\right) f\left(t_{1}, t_{2}, t_{3}\right) d t_{1} d t_{2} d t_{3} \\
=\frac{1}{\Delta T}\left[\int_{T_{i-1}}^{T_{i}} \int_{t_{3}}^{\infty} \int_{t_{3}}^{t_{2}} e^{-r t_{3}}\left(t_{3}-T_{i-1}\right) f_{5}\left(t_{1}, t_{2}, t_{3}\right) d t_{1} d t_{2} d t_{3}\right. \\
\left.\quad+\int_{T_{i-1}}^{T_{i}} \int_{t_{3}}^{\infty} \int_{t_{2}}^{\infty} e^{-r t_{3}}\left(t_{3}-T_{i-1}\right) f_{6}\left(t_{1}, t_{2}, t_{3}\right) d t_{1} d t_{2} d t_{3}\right] \\
:=\frac{1}{\Delta T}\left(I_{8}+I_{9}\right)
\end{gathered}
$$

where

$$
\begin{aligned}
I_{8}=\int_{T_{i-1}}^{T_{i}} \int_{t_{3}}^{\infty} \int_{t_{3}}^{t_{2}} e^{-r t_{3}}\left(t_{3}-T_{i-1}\right) c_{0}\left(a_{0}+a_{2}\right)\left(b_{0}+b_{3}\right) \\
\cdot \cdot e^{-\left(a_{0}+a_{2}+b_{2}-b_{3}\right) t_{1}-\left(b_{0}+b_{3}\right) t_{2}-\left(c_{0}-a_{2}-b_{2}\right) t_{3}} d t_{1} d t_{2} d t_{3} \\
=\frac{c_{0}\left(a_{0}+a_{2}\right)}{a_{0}+a_{2}+b_{0}+b_{2}}\left[\frac{1}{\alpha}\left(e^{-\alpha T_{i}}\left(T_{i-1}-T_{i}\right)+\frac{1}{\alpha}\left(e^{-\alpha T_{i-1}}-e^{-\alpha T_{i}}\right)\right)\right], \\
I_{9}=\int_{T_{i-1}}^{T_{i}} \int_{t_{3}}^{\infty} \int_{t_{2}}^{\infty} e^{-r t_{3}}\left(t_{3}-T_{i-1}\right) c_{0}\left(a_{0}+a_{3}\right)\left(b_{0}+b_{2}\right) \\
\quad \cdot e^{-\left(a_{0}+a_{3}\right) t_{1}-\left(b_{0}+b_{2}+a_{2}-a_{3}\right) t_{2}-\left(c_{0}-a_{2}-b_{2}\right) t_{3}} d t_{1} d t_{2} d t_{3} \\
=\frac{c_{0}\left(b_{0}+b_{2}\right)}{a_{0}+a_{2}+b_{0}+b_{2}}\left[\frac{1}{\alpha}\left(e^{-\alpha T_{i}}\left(T_{i-1}-T_{i}\right)+\frac{1}{\alpha}\left(e^{-\alpha T_{i-1}}-e^{-\alpha T_{i}}\right)\right)\right] .
\end{aligned}
$$

We can obtain

$$
\begin{aligned}
A(\Delta T) & =\sum_{i=1}^{n} E\left[e^{-r \tau^{C}}\left(\frac{\tau^{C}-T_{i-1}}{\Delta T}\right) \nabla_{\left\{T_{i-1}<\tau^{C}<T_{i}\right\}} \nabla_{\left\{\tau^{A} \wedge \tau^{B}>\tau^{C}\right\}}\right] \\
& =\frac{1}{\Delta T} \sum_{i=1}^{n}\left(I_{8}+I_{9}\right) \\
& =\frac{c_{0}\left(1-e^{-\alpha \Delta T}-\alpha \Delta T e^{-\alpha \Delta T}\right)}{\alpha^{2} \Delta T} \frac{1-e^{-\alpha T}}{1-e^{-\alpha \Delta T}} .
\end{aligned}
$$


The right-hand side of (4.20) is

$$
\begin{aligned}
& E\left[e^{-r\left(\tau^{C}+\theta\right)} \sigma_{\left\{\tau^{C} \leq T\right\}}{ }_{\left\{\tau^{A}>\tau^{C}\right\}}{ }_{\left\{\tau^{B}>\tau^{C}+\theta\right\}}\right] \\
& \quad=\left[\frac{c_{0} e^{-\left(a_{0}+a_{2}+b_{0}+b_{2}+r\right) \theta}}{a_{0}+a_{2}+b_{0}+b_{2}}\left(b_{0}+b_{2}-\frac{\left(a_{0}+a_{2}\right)\left(b_{0}+b_{3}\right)}{a_{0}+a_{2}+b_{2}-b_{3}}\right)+\frac{c_{0}\left(a_{0}+a_{2}\right) e^{-\left(b_{0}+b_{3}+r\right) \theta}}{a_{0}+a_{2}+b_{2}-b_{3}}\right] \frac{1-e^{-\alpha T}}{\alpha} .
\end{aligned}
$$

From (4.22)-(4.26), we can obtain the expression of $S(\Delta T)$ from the following equation:

$$
\begin{aligned}
& S(\Delta T)\left[e^{-\alpha \Delta T}+\frac{c_{0}\left(1-e^{-\alpha \Delta T}-\alpha \Delta T e^{-\alpha \Delta T}\right)}{\alpha^{2} \Delta T}\right] \frac{e^{-\alpha \Delta T}\left(1-e^{-\alpha T}\right)}{1-e^{-\alpha \Delta T}} \\
& \quad=\left[\frac{c_{0} e^{-\left(a_{0}+a_{2}+b_{0}+b_{2}+r\right) \theta}}{a_{0}+a_{2}+b_{0}+b_{2}}\left(b_{0}+b_{2}-\frac{\left(a_{0}+a_{2}\right)\left(b_{0}+b_{3}\right)}{a_{0}+a_{2}+b_{2}-b_{3}}\right)+\frac{c_{0}\left(a_{0}+a_{2}\right) e^{-\left(b_{0}+b_{3}+r\right) \theta}}{a_{0}+a_{2}+b_{2}-b_{3}}\right] \cdot \frac{1-e^{-\alpha T}}{\alpha} .
\end{aligned}
$$

Remark 4.6. As analyzed in the continuous time, the expression for the swap premium $S(\Delta T)$ in (4.27) shows no dependence on $a_{1}, a_{3}, b_{1}, c_{1}, c_{2}, c_{3}$. In the financial sense, prior to the default of the underlying asset, the default event of the protection buyer or the protection seller will terminate the contract. This is why $a_{1}, a_{3}, b_{1}, c_{1}, c_{2}, c_{3}$ have no influence on the swap premium. Moreover, we discover that the swap premium is also insensitive to maturity.

\section{Conclusion}

In this paper, we present a three-firms contagion model with an interaction term which is an improvement in the model of Leung and Kwok [18]. Under this model, we analyze the pricing of defaultable bonds and obtain the closed forms. We also discuss the CDS valuation in continuous time and discrete time framework, respectively. The analytical solutions of CDS swap rate (swap premium) are obtained by the approaches of "total hazard construction" and "change of measure." Besides, we analyze the effect of the default of the protection buyer, the protection seller, and the reference asset on the swap rate.

Our model has its actual background. For example, before and during the global financial crisis, as default risk of the reference asset issuer increased, the protection seller collected higher CDS swap premiums. Thus, default risk of the protection buyer increased since more CDS swap premiums were payed. On the other hand, the protection seller compensated more and more for the loss of reference asset (if it defaulted). When the protection seller (such as a monoline insurer) had no ability to compensate for the loss of reference asset, it went bankrupt. All of these could be important reasons for the financial crisis. So our model is of some significance.

\section{Acknowledgment}

This paper was supported by the National Basic Research Program of China (973 program 2007CB814903). 


\section{References}

[1] R. Merton, "On the pricing of corporate debt: the risk structure of interest rates," The Journal of Finance, vol. 29, pp. 449-470, 1974.

[2] F. Black and J. Cox, "Valuing corporate securities: some effects of bond indenture provisions," The Journal of Finance, vol. 31, pp. 351-367, 1976.

[3] R. Geske, "The valuation of corporate liabilities as compound options," Journal of Financial and Quantitative Analysis, vol. 12, pp. 541-552, 1977.

[4] P. Artzner and F. Delbaen, "Default risk insurance and incomplete markets," Mathematical Finance, vol. 5, pp. 187-195, 1995.

[5] D. Duffie, M. Schroder, and C. Skiadas, "Recursive valuation of defaultable securities and the timing of resolution of uncertainty," The Annals of Applied Probability, vol. 6, no. 4, pp. 1075-1090, 1996.

[6] R. Jarrow and S. Turnbull, "Pricing options on financial securities subject to default risk," The Journal of Finance, vol. 50, pp. 53-86, 1995.

[7] D. Madan and H. Unal, "Pricing the risk of default," Review of Derivatives Research, vol. 2, pp. 121-160, 1995.

[8] D. Duffie and D. Lando, "Term structures of credit spreads with incomplete accounting information," Econometrica, vol. 69, no. 3, pp. 633-664, 2001.

[9] R. A. Jarrow, D. Lando, and S. M. Turnbull, “A Markov model for the term structure of credit risk spreads," Review of Financial Studies, vol. 10, no. 2, pp. 481-523, 1997.

[10] R. Litterman and T. Iben, "Corporate bond valuation and term structure of credit spreads," The Journal of Portfolio Management, vol. 17, no. 3, pp. 52-64, 1991.

[11] D. Duffie and K. J. Singleton, "Modeling term structures of defaultable bonds," Review of Financial Studies, vol. 12, no. 4, pp. 687-720, 1999.

[12] D. Lando, "On cox processes and credit risky securities," Review of Derivatives Research, vol. 2, no. 2-3, pp. 99-120, 1998.

[13] P. Collin-Dufresne and B. Solnik, "On the term structure of default premia in the swap and LIBOR markets," The Journal of Finance, vol. 56, no. 3, pp. 1095-1115, 2001.

[14] G. R. Duffee, “Estimating the price of default risk," Review of Financial Studies, vol. 12, no. 1, pp. 197226, 1999.

[15] R. A. Jarrow and F. Yu, "Counterparty risk and the pricing of defaultable securities," The Journal of Finance, vol. 56, no. 5, pp. 1765-1799, 2001.

[16] R. J. Elliott, M. Jeanblanc, and M. Yor, “On models of default risk," Mathematical Finance, vol. 10, no. 2, pp. 179-195, 2000.

[17] F. Jamshidian, Valuation of Credit Default Swaps and Swaptions Preprint, NIB Capital Bank, The Hagve, The Netherlands, 2003.

[18] S. Y. Leung and Y. K. Kwok, "Credit default swap valuation with counterparty risk," The Kyoto Economic Review, vol. 74, pp. 25-45, 2005.

[19] J. M. Harrison and D. M. Kreps, "Martingales and arbitrage in multiperiod securities markets," Journal of Economic Theory, vol. 20, no. 3, pp. 381-408, 1979.

[20] J. M. Harrison and S. R. Pliska, "Martingales and stochastic integrals in the theory of continuous trading," Stochastic Processes and Their Applications, vol. 11, no. 3, pp. 215-260, 1981.

[21] F. Yu, "Correlated defaults and the valuation of defaultable securities," Working Paper, University of California at Irvine, 2004.

[22] I. Norros, "A compensator representation of multivariate life length distributions, with applications," Scandinavian Journal of Statistics, vol. 13, no. 2, pp. 99-112, 1986.

[23] M. Shaked and J. G. Shanthikumar, "The multivariate hazard construction," Stochastic Processes and Their Applications, vol. 24, no. 2, pp. 241-258, 1987.

[24] F. Yu, "Correlated defaults in intensity-based models," Mathematical Finance, vol. 17, no. 2, pp. 155$173,2007$.

[25] P. Collin-Dufresne, R. Goldstein, and J. Hugonnier, "A general formula for valuing defaultable securities," Econometrica, vol. 72, no. 5, pp. 1377-1407, 2004.

[26] R. Jarrow and Y. Yildirim, "A simple model for valuing default swaps when both market and credit risk are correlated," Journal of Fixed Income, vol. 11, no. 4, pp. 7-19, 2002.

[27] J. Hull and A. White, "Valuing credit default swaps II: modeling default correlations," Journal of Derivatives, vol. 8, pp. 12-22, 2001.

[28] M. A. Kim and T. S. Kim, "Credit default swap valuation with counterparty default risk and market risk," Journal of Risk, vol. 6, no. 2, pp. 49-80, 2003. 
[29] L. Chen and D. Filipovic, "Pricing credit default swaps under default correlations and counterparty risk," Working Paper, Princeton University, 2003.

[30] M. A. Petersen, J. Mukuddem-Petersen, M. P. Mulaudzi, B. de Waal, and I. M. Schoeman, "Subprime risk and insurance with regret," Discrete Dynamics in Nature and Society, vol. 2010, Article ID 950413, 52 pages, 2010.

[31] H. Zheng and L. Jiang, "Basket CDS pricing with interacting intensities," Finance and Stochastics, vol. 13, no. 3, pp. 445-469, 2009. 


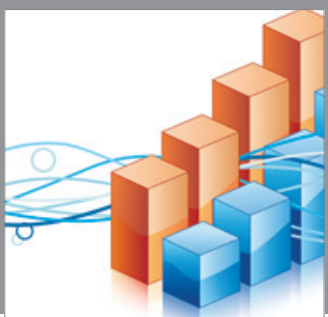

Advances in

Operations Research

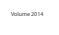

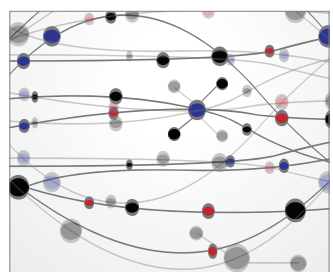

\section{The Scientific} World Journal
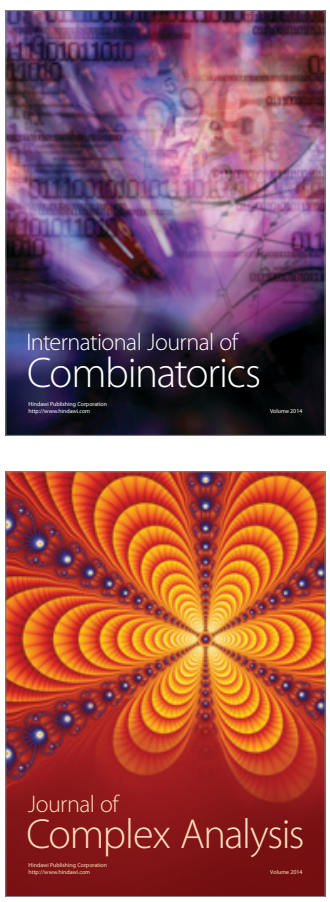

International Journal of

Mathematics and

Mathematical

Sciences
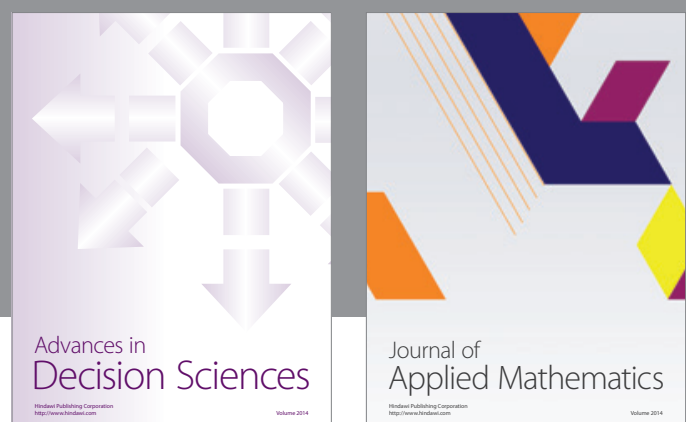

Journal of

Applied Mathematics
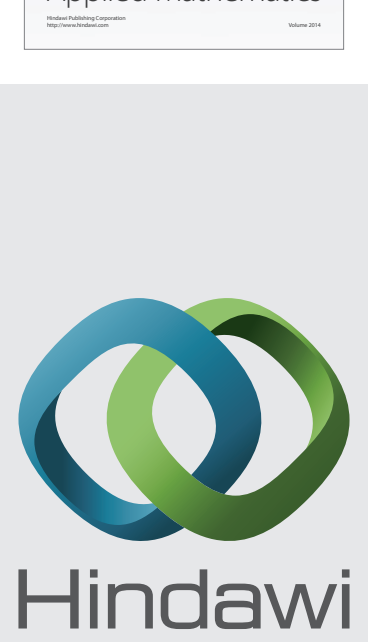

Submit your manuscripts at http://www.hindawi.com
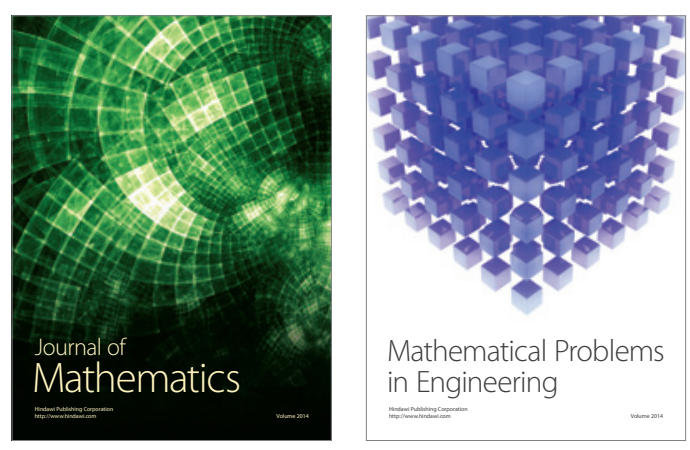

Mathematical Problems in Engineering
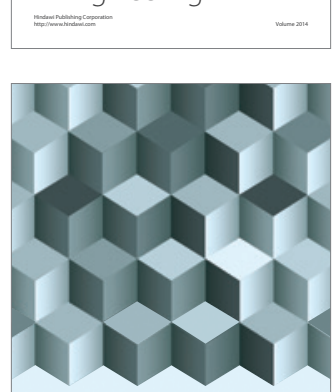

Journal of

Function Spaces
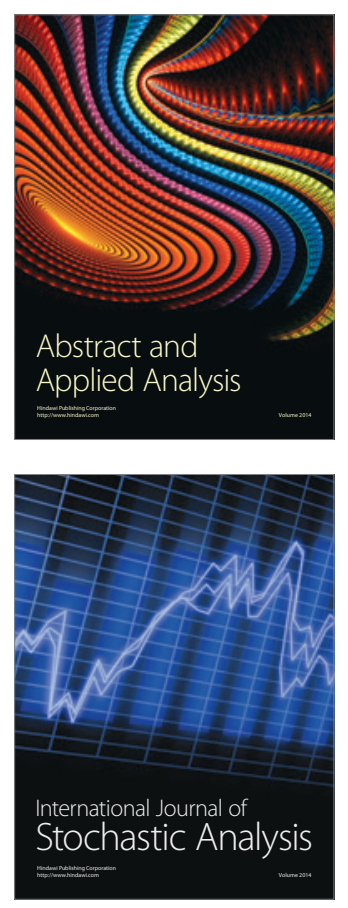

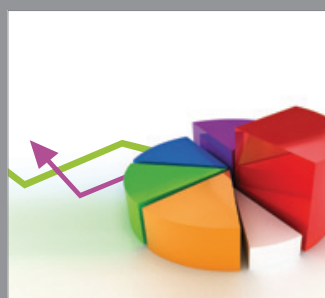

ournal of

Probability and Statistics

Promensencen
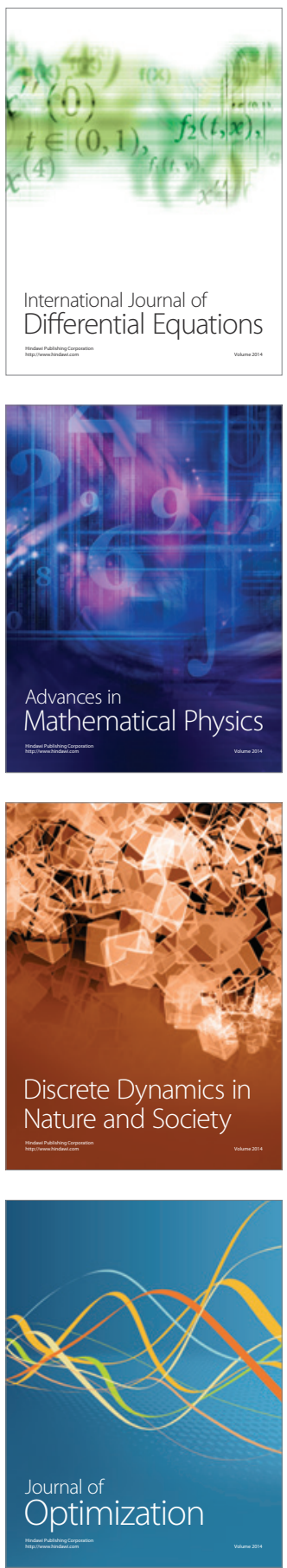